\title{
PLD1 Negatively Regulates Dendritic Branching
}

\author{
Yan-Bing Zhu, ${ }^{1 \star}$ Kai Kang, ${ }^{1 *}$ Ying Zhang, ${ }^{1}$ Cai Qi, ${ }^{1}$ Gang Li, ${ }^{1}$ Dong-Min Yin, ${ }^{2}$ and Yun Wang ${ }^{1}$ \\ ${ }^{1}$ Neuroscience Research Institute and Department of Neurobiology, Key Laboratory for Neuroscience of Ministry of Education and Health, School of Basic \\ Medical Sciences, Peking University, Beijing 100191, China and 2Institute of Molecular Medicine and Genetics, Georgia Health Sciences University, Augusta, \\ Georgia 30912
}

Neurons have characteristic dendritic arborization patterns that contribute to information processing. One essential component of dendritic arborization is the formation of a specific number of branches. Although intracellular pathways promoting dendritic growth and branching are being elucidated, the mechanisms that negatively regulate the branching of dendrites remain enigmatic. In this study, using gain-of-function and loss-of-function studies, we show that phospholipase D1 (PLD1) acts as a negative regulator of dendritic branching in cultured hippocampal neurons from embryonic day 18 rat embryos. Overexpression of wild-type PLD1 (WT-PLD1) decreases the complexity of dendrites, whereas knockdown or inhibition of PLD1 increases dendritic branching. We further demonstrated that PLD1 acts downstream of RhoA, one of the small Rho GTPases, to suppress dendritic branching. The restriction of dendritic branching by constitutively active RhoA (V14-RhoA) can be partially rescued by knockdown of PLD1. Moreover, the inhibition of dendritic branching by V14-RhoA and WT-PLD1 can be partially ameliorated by reducing the level of phosphatidic acid (PA), which is the enzymatic product of PLD1. Together, these results suggest that RhoA-PLD1-PA may represent a novel signaling pathway in the restriction of dendritic branching and may thus provide insight into the mechanisms of dendritic morphogenesis.

\section{Introduction}

Dendritic morphogenesis is an important step for the establishment of neural circuitry. The numbers of primary dendrites arising from the cell body, higher order dendrites emerging from primary dendrites, and dendritic branching patterns appear to be critical for neuronal function (Jan and Jan, 2010). Although intracellular pathways promoting dendritic growth and branching are being elucidated, the mechanisms that restrict the overgrowth of dendrites remain enigmatic.

The small GTPases of the Rho subfamily are critical regulators of dendritic morphogenesis (Luo, 2000). The best studied Rho GTPases are RhoA, Rac1, and Cdc42. Among these Rho GTPases, RhoA is unique in its ability to inhibit dendritic branching both in cultured neurons and mosaic Drosophila brains (Lee et al., 2000; Li et al., 2000). Exactly how RhoA negatively regulates dendritic branching is not comprehensively defined. Several kinases downstream of RhoA have been identified including Rho kinase

Received Oct. 25, 2011; revised April 23, 2012; accepted April 25, 2012.

Author contributions: Y.-B.Z., K.K., Y.Z., D.-M.Y., and Y.W. designed research; Y.-B.Z., K.K., Y.Z., C.Q., and G.L. performed research; Y.-B.Z., K.K., Y.Z., C.Q., G.L., D.-M.Y., and Y.W. analyzed data; Y.-B.Z., K.K., D.-M.Y., and Y.W. wrote the paper.

This work was supported by the National Natural Science Foundation of China, Grants 81161120497, 30830044, 30900582, and 30925015; the Beijing Natural Science Foundation, Grant 7092061; the National Basic Research 973 Program of China, Grant 2007CB512100; and the Specialized Research Fund for Doctoral Program of Higher Education, Grants 200800011028 and 20060001121 . We thank Dr. Jonathan C. Bean for providing English-language editing.

*Y-B.Z. and K.K. contributed equally to this work.

The authors declare no competing financial interests.

Correspondence should be addressed to either of the following: Dr. Yun Wang, Neuroscience Research Institute, Peking University, 38 Xueyuan Road, Beijing 100191, China, E-mail: wangy66@bjmu.edu.cn; or Dr. Dong-Min Yin, Institute of Molecular Medicine and Genetics, Georgia Health Sciences University, Augusta, Georgia 30912, E-mail: dyin@georgiahealth.edu.

DOI:10.1523/JNEUROSCI.5378-11.2012

Copyright $\odot 2012$ the authors $\quad 0270-6474 / 12 / 327960-10 \$ 15.00 / 0$
(Matsui at el., 1996) and LIM kinase 1 (Maekawa et al., 1999; Ohashi et al., 2000). However, the roles of several proteins downstream of RhoA in dendritic branching have not been confirmed by genetic studies. For example, dendritic branching is normal in LIM kinase 1 knock-out neurons (Meng et al., 2002). Although compensatory mechanisms may exist, this finding led us to examine the role of other signaling molecules downstream of RhoA in the regulation of dendritic branching.

In addition to kinases, the lipid-mediated second messenger system represents one of the major mechanisms of cellular signaling. Phospholipase D (PLD), which catalyzes the hydrolysis of phosphatidylcholine (PC) to generate phosphatidic acid (PA) and choline, has emerged as a signal transduction phospholipase in recent studies (Cockcroft, 1996; Exton, 1999; Rudge and Wakelam, 2009). PLD isozymes, including PLD1 and PLD2, are present in many types of mammalian cells, including neurons (Meier et al., 1999). Recently, both PLD1 and PLD2 have been implicated in the regulation of neurite growth in neural cell lines (Hayakawa et al., 1999; Gibbs and Meier, 2000) and neural stem cells (Sung et al., 2001; Yoon et al., 2005) and the seizure-induced sprouting of mossy fibers (Zhang et al., 2004, 2005).

In the present study, we focused on PLD1 because it can be directly activated by RhoA both in vitro and in vivo (Hammond et al., 1997; Bae et al., 1998; Yamazaki et al., 1999; Du et al., 2000; Komati et al., 2005; Yoon et al., 2005; Gayral et al., 2006). Using cultured hippocampal neurons as a cellular model, we found that PLD1 negatively regulated dendritic branching. The inhibition of dendritic growth by PLD1 is consistent with the reduction of its expression and activity during dendritic maturation. Further experiments indicated that PLD1 partially contributed to the role of RhoA in dendritic arborization. PA, the enzymatic product of PLD1, appears to be important in mediating the effects of RhoA and PLD1 
A
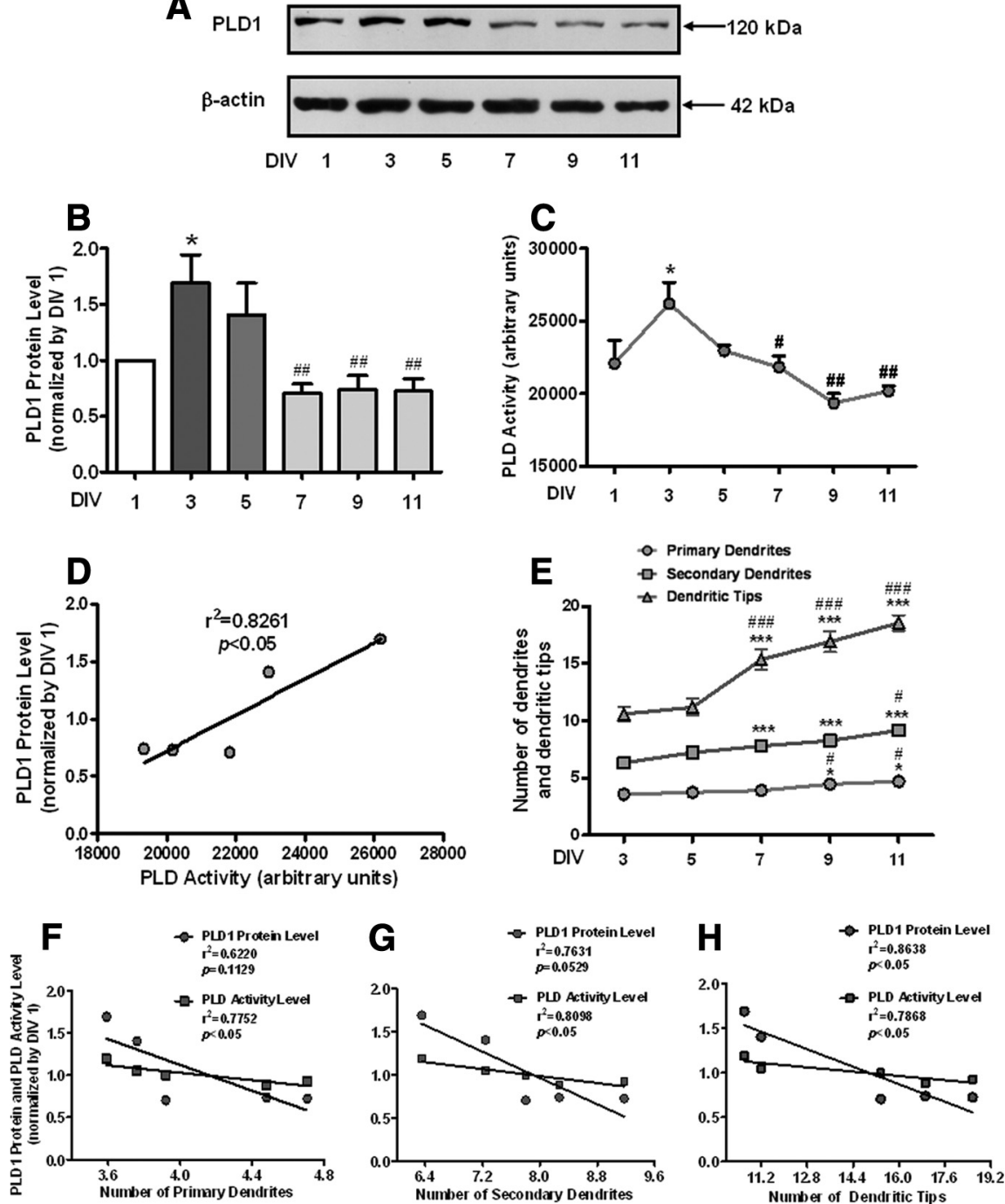

Figure 1. Protein level and activity of PLD1 during the development of hippocampal neurons. $A$, Western blot analysis of PLD1 in developing hippocampal neurons at indicated time points. $\boldsymbol{B}$, Quantification of PLD1 protein levels during the development of hippocampal neurons. $n=7$ samples each time point. ${ }^{*} p<0.05$, between DIV 3 and DIV $1 .{ }^{\#} p<0.01$, between DIV 7 and DIV 3, DIV 9 and DIV3, DIV11 and DIV3, and one-way ANOVA followed by Newman-Keuls multiple-comparison test. C, Quantification of PLD activity in developing hippocampal neurons. $n=3$ samples each time point. ${ }^{*} p<0.05$, between DIV 3 and DIV $1 .{ }^{*} p<$ 0.05 , between DIV 7 and DIV 3 . ${ }^{\# \#} p<0.01$, between DIV 9 and DIV3, DIV 11 and DIV 3 , and one-way ANOVA followed by Newman-Keuls multiple-comparison test. $\boldsymbol{D}$, The correlation between PLD1 protein levels and PLD activities $\left(r^{2}=0.8261, p<\right.$ $0.05)$. $E$, Quantification of primary dendrites, secondary dendrites, and dendritic tips from DIV 3 to DIV 11. DIV $3, n=22 ;$ DIV $5, n=$ 25 ; DIV $7, n=24$; DIV $9, n=25$; DIV $11, n=18$. ${ }^{*} p<0.05$, between DIV 9,11 and DIV $3 .{ }^{*} p<0.05$, between DIV 9,11 and DIV 5 in primary dendrites. ${ }^{* *} p<0.001$, between DIV 7,9,11 and DIV $3 .{ }^{*} p<0.05$, between DIV 11 and DIV 5 in secondary dendrites. ${ }^{* * *} p<0.001$, between DIV 7,9, 11 and DIV 3 . ${ }^{\# \#} p<0.001$, between DIV 7, 9,11 and DIV 5 in dendritic tips, one-way ANOVA followed by Newman-Keuls multiple-comparison test. $\boldsymbol{F}-\boldsymbol{H}$, The correlation between the number of dendrites or dendritic tips and PLD1 protein levels or PLD activities from DIV 3 to DIV 11. $F$, Primary dendrites: PLD1 protein level: $r^{2}=0.6220, p=0.1129$; PLD activity: $r^{2}=0.7752, p<0.05$. G, Secondary dendrites: PLD1 protein level: $r^{2}=0.7631, p=0.0529$; PLD activity: $r^{2}=$ $0.8098, p<0.05$. H, Dendritic tips: PLD1 protein level: $r^{2}=0.8638, p<0.05 ;$ PLD activity: $r^{2}=0.7868, p<0.05$.

in dendritic branching. Overall, these results indicate that RhoA, PLD1, and PA may constitute one signaling pathway in the regulation of dendritic branching.

\section{Materials and Methods}

Antibodies and chemicals. We used the following antibodies and chemicals: rabbit polyclonal anti-PLD1 (\#3832; Cell Signaling Technology), mouse monoclonal anti- $\beta$-actin (Sigma-Aldrich), mouse monoclonal antiRhoA (sc-418; Santa Cruz Biotechnology), rabbit polyclonal anti-HA (sc-805; Santa Cruz Biotechnology), mouse monoclonal anti-Myc
(Zhongshan Golden Bridge Biotechnology), and 1-butanol and 2-butanol were purchased from Sigma-Aldrich.

DNA constructs. Hemagglutinin (HA)tagged wild-type PLD1 (WT-PLD1) and HAtagged dominant-negative PLD1 (DN-PLD1) were generously provided by Dr. Michael A. Frohman (Stony Brook University, Stony Brook, NY). To create siRNA-resistant PLD1 (RES-PLD1), the third nucleotide of each codon in the target sequence was mutated without changing the identity of the amino acids. cDNA of the constitutively active RhoA mutant (V14-RhoA) and the dominantnegative mutant of RhoA (N19-RhoA) were generously provided by Dr. Huaye Zhang (Department of Neuroscience and Cell Biology, Robert Wood Johnson Medical School, University of Medicine and Dentistry of New Jersey). The cDNA of V14-RhoA and N19-RhoA were subcloned to pcDNA3.1/Myc-His C (Clontech) to generate the Myc-His-RhoA fusion constructs, which were verified by DNA sequencing.

Neuronal culture and transfection. Hippocampal explants isolated from embryonic day 18 rat embryos of either sex were digested with $0.25 \%$ trypsin for $30 \mathrm{~min}$ at $37^{\circ} \mathrm{C}$ followed by trituration with a pipette in plating medium (DMEM with 10\% fetal bovine serum[FBS]). Dissociated neurons were plated onto $35 \mathrm{~mm}$ dishes coated with poly-D-lysine (SigmaAldrich) at a density of $5 \times 10^{5}$ cells per dish. After culturing for $4 \mathrm{~h}$, media were changed to Neurobasal medium supplemented with $2 \%$ B27 and 0.5 mm GlutaMAX-I (Invitrogen). To test the role of PLD1 in dendritic branching, neurons were cotransfected with the DNA of interest and pEGFP-N1 at $3 \mathrm{~d}$ or $6 \mathrm{~d}$ in vitro (DIV) were fixed with $4 \%$ paraformaldehyde and subjected to analysis of dendritic branching $3 \mathrm{~d}$ after transfection. Lipofectamine 2000 (Invitrogen) was used for neuronal transfection following the instructions provided by the manufacturer. To address the effects of pharmacological inhibitors on dendritic numbers, DIV 6 hippocampal neurons were treated with 1-butanol or 2-butanol in the culture medium for $3 \mathrm{~d}$ before the analysis of dendritic branching.

RNA interference. The sequence of PLD1 small interfering RNA (siRNA) was as follows: $5^{\prime}$-CUGGAAGAUUACUUGACAA- ${ }^{\prime}$. . siRNA with the sequence of $5^{\prime}$-UUCUCCGAA CGUGUCACGU-3' was used as a control because it is unable to knock down the expression of any known proteins. In the RNA interference experiments, PLD1 siRNA or control siRNA was transfected together with pEGFPN1. For the rescue experiments, PLD1 siRNA, RES-PLD1, and pEGFP-N1 were transfected together with Lipofectamine 2000.

Western blot analysis. Cell cultures were washed twice with ice-cold PBS containing (in mM): $137 \mathrm{NaCl}, 2.7 \mathrm{KCl}, 10 \mathrm{Na}_{2} \mathrm{HPO}_{4}$, and $2 \mathrm{KH}_{2} \mathrm{PO}_{4}$ and lysed in ice-cold lysis buffer (50 mm Tris-HCl, pH 7.4, $150 \mathrm{~mm} \mathrm{NaCl}, 1.5 \mathrm{~mm}$ $\mathrm{MgCl}_{2}, 10 \%$ glycerol, $1 \%$ Triton X-100, 5 mM EGTA, $1 \mu \mathrm{g} / \mathrm{ml}$ leupeptin, 1 mм PMSF, $1 \mathrm{~mm} \mathrm{Na}_{3} \mathrm{VO}_{4}, 10 \mathrm{~mm} \mathrm{NaF}$, and proteinase inhibitor mixture). The lysates were centrifuged at $12,000 \times g$ for $5 \mathrm{~min}$ to yield the total protein extract in the supernatant. The concentration of protein was measured with a BCA assay kit (Pierce). Equal amounts of samples $(50 \mu \mathrm{g})$ were denatured 


\section{DIV $3+3$}
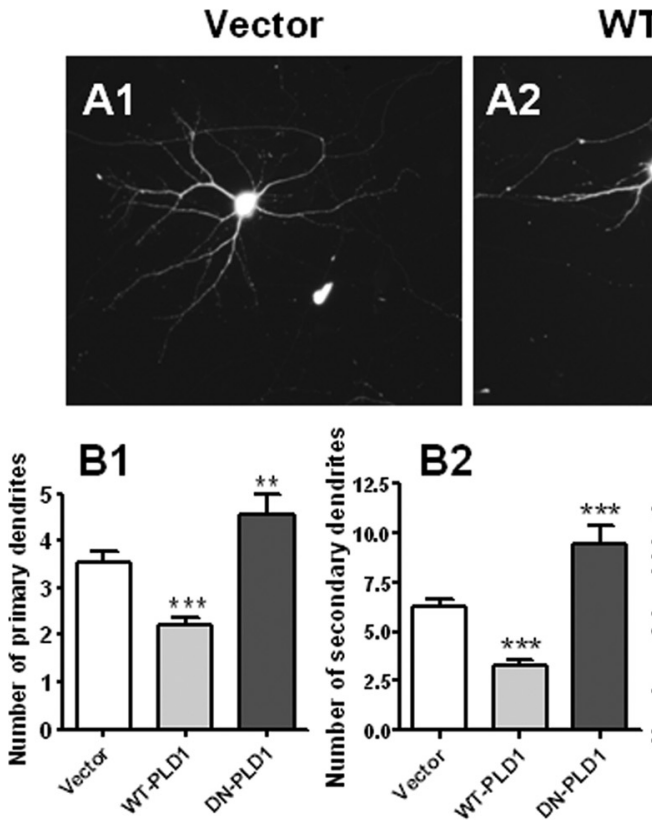

WT-PLD1

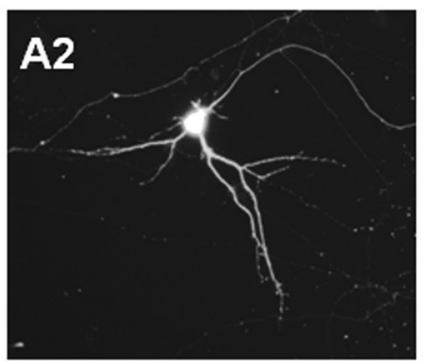

B3

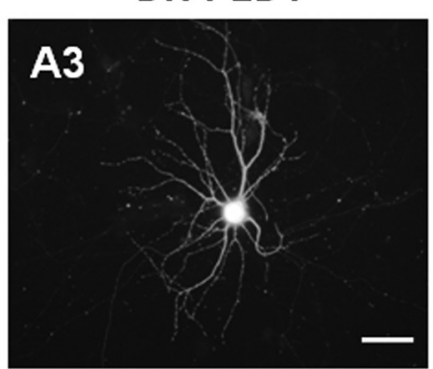

B4

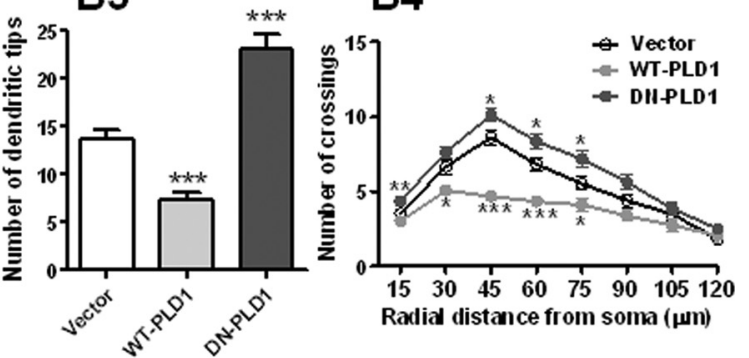

DIV 6+3
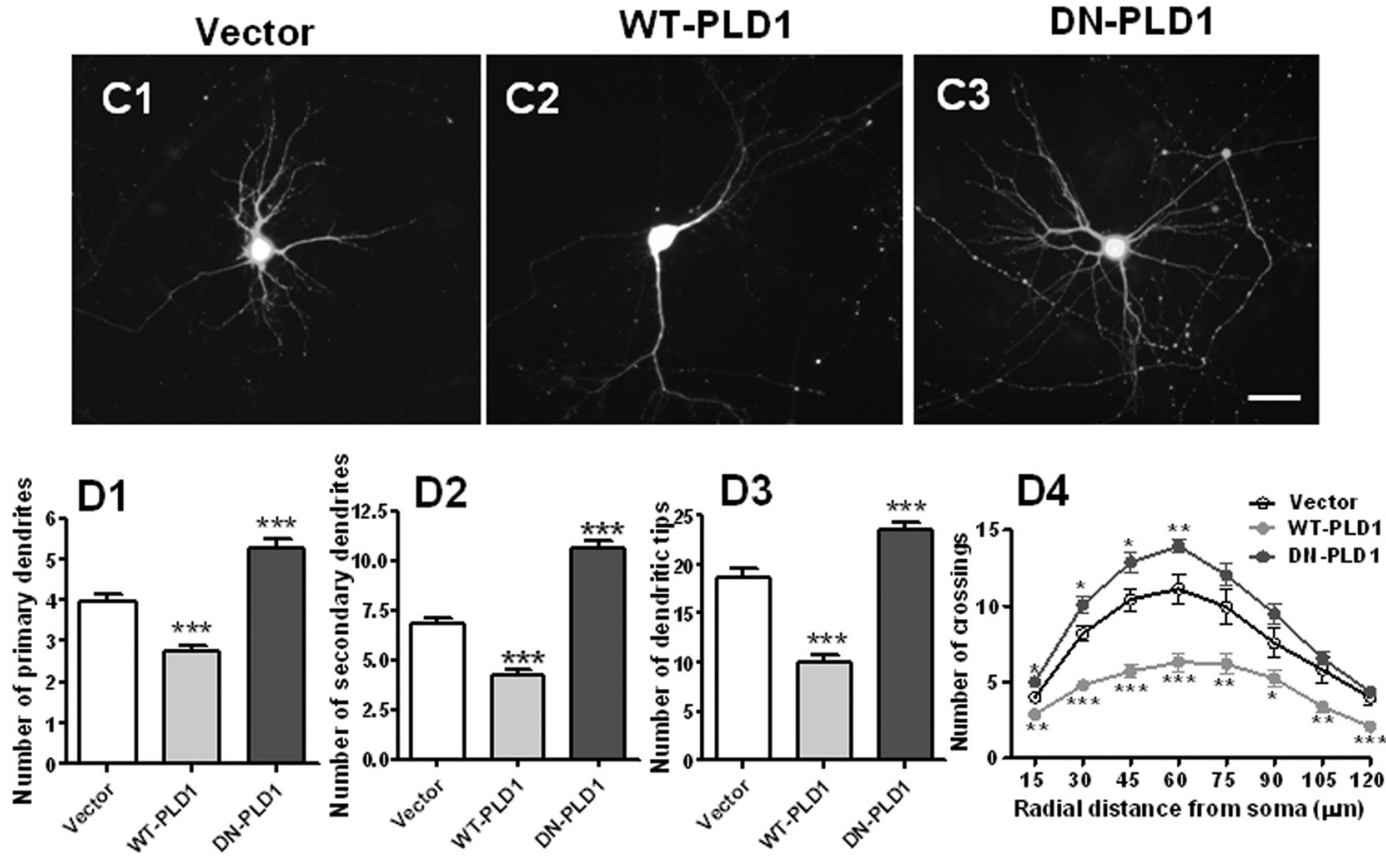

Figure 2. Effects of WT-PLD1 and DN-PLD1 on the dendritic branching of hippocampal neurons.A1-A3, Representative images of DIV 6 neurons transfected with HA-Vector (A1), HA-tagged WT-PLD1 (A2), or HA-tagged DN-PLD1 (A3) at DIV 3. Scale bar, $50 \mu \mathrm{m}$. B1-B4, Quantification of primary dendrites (B1), secondary dendrites (B2), dendritic tips (B3), and Sholl analysis (B4) in $\boldsymbol{A}$. $n=22$ neurons for control, $n=45$ neurons for WT-PLD1, $n=14$ neurons for DN-PLD1, ${ }^{*} p<0.05,{ }^{* *} p<0.01,{ }^{* * *} p<0.001$, compared with control group, $t$ tests. C1-C3, Representative images of DIV 9 neurons transfected with HA-Vector (C1), HA tagged WT-PLD1 (C2), or HA tagged DN-PLD1 (C3) at DIV 6. Scale bar, $50 \mu \mathrm{m}$. D1-D4, Quantification of primary dendrites (D1), secondary dendrites (D2), dendritic tips (D3), and Sholl analysis (D4) in C. $n=37$ neurons for control, $n=42$ neurons for WT-PLD1, $n=32$ neurons for DN-PLD1, ${ }^{*} p<0.05,{ }^{* *} p<0.01,{ }^{* * *} p<0.001$, compared with control group, $t$ test.

and subjected to $10 \%$ SDS-PAGE. After separation, proteins were transferred to nitrocellulose membranes (Bio-Rad). The membranes were blocked with 5\% nonfat milk in TBST (25 mM Tris-HCl, pH 7.4, $137 \mathrm{~mm}$ $\mathrm{NaCl}, 2.7 \mathrm{~mm} \mathrm{KCl}$, and $0.05 \%$ Tween 20 ) for $1 \mathrm{~h}$ at room temperature and incubated with primary antibody overnight at $4^{\circ} \mathrm{C}$. After washing with TBST three times, the membranes were incubated with horseradish peroxidase (HRP)-conjugated secondary antibody for $1 \mathrm{~h}$ at room temperature, washed again, and finally were developed with ECL solutions (ThermoFisher Scientific). The immunoreactive bands were scanned and analyzed quantitatively by densitometry with Quantity One (Bio-Rad).
Cell culture and coimmunoprecipitation. Neuroblastoma N2a cells were cultured at $37^{\circ} \mathrm{C}$ in $60 \mathrm{~mm}$ dishes in a humidified atmosphere of $95 \%$ air and $5 \% \mathrm{CO}_{2}$. The culture medium was DMEM with $10 \%$ FBS. Myc-His-V14-RhoA was coexpressed with HA-Vector, HA-WTPLD1, or HA-DN-PLD1 in N2a cells. Thirty-six hours after transfection, cells were harvested in ice-cold lysis buffer, and the homogenates were centrifuged at $12,000 \times g$ for $5 \mathrm{~min}$ to yield the total protein extract in the supernatant. Cellular extracts were mixed with anti-Myc antibody $(1: 100)$ at $4^{\circ} \mathrm{C}$ for $3 \mathrm{~h}$ before incubation with Protein A-Sepharose CL-4B resin (GE Healthcare) overnight. The 
A1 amino acids $L \quad E \quad D \quad Y \quad L \quad T$ WT-PLD1 CTG GAA GAI TAC TTG ACAA RES-PLD1 CTG GAG GAC TAI TTG ACAA

A3

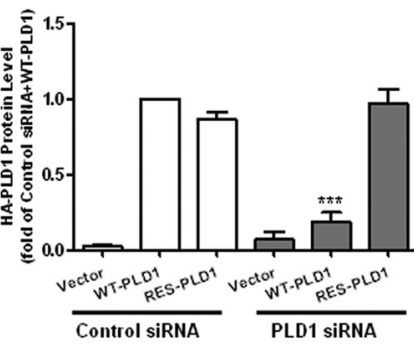

A4

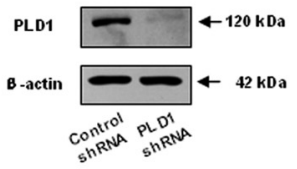

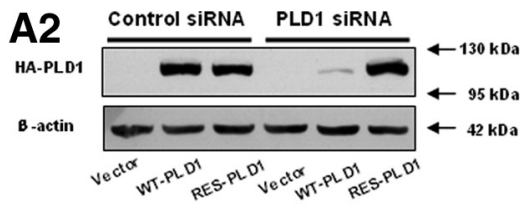

Control siRNA
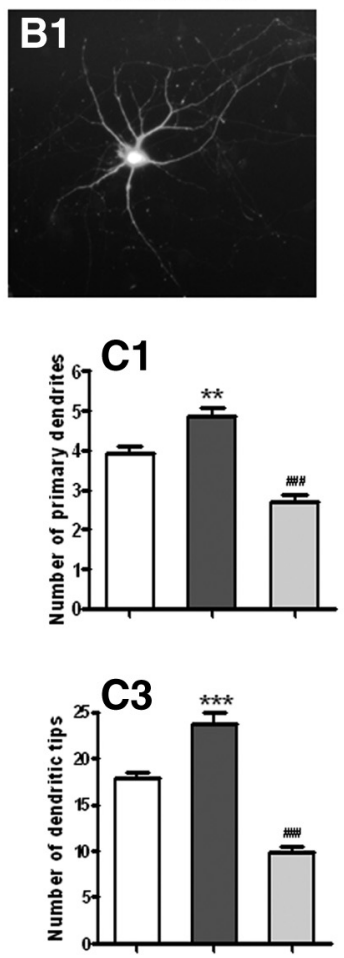

PLD1 siRNA
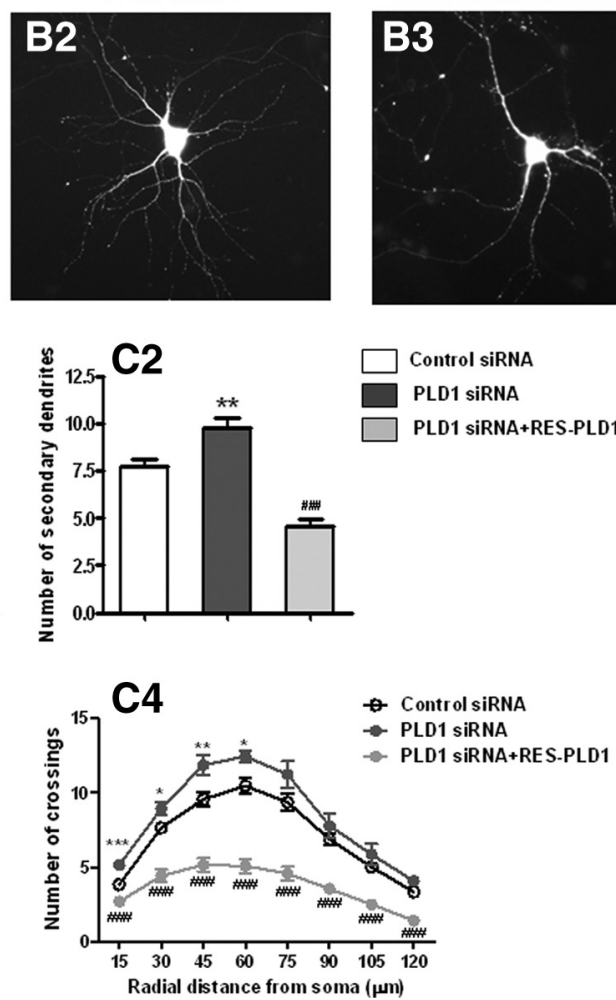

Figure 3. Effects of PLD1 siRNA on the dendritic branching of hippocampal neurons. A1, Comparison of the target sequence between WT-PLD1 and RES-PLD1. The third nucleotide in each codon was mutated in RES-PLD1 without altering the identity of amino acids. $A 2, A 3$, Knockdown effect of WT-PLD1 but not RES-PLD1 (siRNA-resistant PLD1) by PLD1 siRNA. $n=5,{ }^{* * *} p<0.001$, compared with WT-PLD1 plus Control siRNA, one-way ANOVA followed by Newman-Keuls multiple-comparison test. $\boldsymbol{A 4 ,} \mathbf{A 5}$, Knockdown effect of endogenous PLD1 in hippocampal neurons by PLD1 shRNA. $n=3,{ }^{* *} p<0.01$, compared with Control shRNA, $t$ test. $\boldsymbol{B} 1-\boldsymbol{B} 3$, Representative images of DIV 9 neurons transfected with Control siRNA (B1), PLD1 siRNA (B2), or PLD1 siRNA + RES-PLD1 (B3). Scale bar, $50 \mu \mathrm{m}$. C1-C4, Quantification of primary dendrites (C1), secondary dendrites (C2), dendritic tips (C3), and Sholl analysis (C4) in B. $n=37$ for Control siRNA, $n=19$ for PLD1 siRNA, $n=47$ for PLD1 siRNA + RES-PLD1, ${ }^{*} p<$ $0.05,{ }^{* *} p<0.01,{ }^{* * *} p<0.001$, compared with Control siRNA, $t$ test; ${ }^{\# \# \#} p<0.001$, compared with PLD1 siRNA, $t$ test.

beads were washed six times with TBS containing $0.1 \%$ Triton X-100 before boiling with $2 \times$ SDS buffer for $10 \mathrm{~min}$. After centrifugation at $3000 \times g$ for $2 \mathrm{~min}$, the supernatant was decanted and subjected to Western blot analysis.

PLD activity assay. Following the nonradioactive method, PLDmediated PA production was analyzed with a fluorescent in vitro assay (Elvers et al., 2010). In this enzymatically coupled assay, PLD hydrolyzes $\mathrm{PC}$ in the presence of $\mathrm{PI}(4,5) \mathrm{P}_{2}$ to $\mathrm{PA}$ and choline, which is subsequently oxidized by choline oxidase to betaine and $\mathrm{H}_{2} \mathrm{O}_{2}$. In the presence of HRP, $\mathrm{H}_{2} \mathrm{O}_{2}$ oxidizes Amplex red in a 1:1 stoichiometry to generate fluorescent resorufin (7-hydroxy-3H-phenoxazin-3-one). Because resorufin has absorption and fluorescence emission maxima of $\sim 571$ and $585 \mathrm{~nm}$, respectively, which is beyond the range of the autofluorescence from most biological samples, this fluorescent assay specifically detects PLD activity. In brief, equal amounts of cell lysates $(100 \mu \mathrm{g})$ were mixed with $100 \mu \mathrm{l} \mathrm{Am-}$ plex red reaction buffer from the Amplex Red PLD assay kit (Invitrogen). After incubation at $37^{\circ} \mathrm{C}$ in darkness for $45 \mathrm{~min}$, the fluorescence was measured in a fluorescence microplate reader using excitation in the range of 530-560 $\mathrm{nm}$ and emission detection at $\sim 590 \mathrm{~nm}$. Each sample was duplicated to create average fluorescence values.

Measurement of PA. Neurons were harvested using a rubber policeman. After protein determination, $1.5 \mathrm{ml}$ of methanol, $2.25 \mathrm{ml}$ of $1 \mathrm{M}$ $\mathrm{NaCl}$, and $2.5 \mathrm{ml}$ of chloroform were used to separate cellular lipids. The sample was centrifuged at $1500 \mathrm{~g}$, and the lower phase was dried under a gentle stream of nitrogen. Lipids were resuspended with $1 \%$ Triton X-100. Following the nonradioactive method, PA concentration was analyzed with a fluorescent in vitro assay. In this enzymatically coupled assay, lipase is used to hydrolyze PA to glycerol-3phosphate, which is subsequently oxidized by glycerol-3-phosphate oxidase to generate $\mathrm{H}_{2} \mathrm{O}_{2}$. In the presence of peroxidase, $\mathrm{H}_{2} \mathrm{O}_{2}$ reacts with 10-acetyl-3,7-dihydroxyphenoxazine to yield the highly fluorescent compound resorufin (Morita et al., 2009). Resorufin fluorescence can be analyzed using excitation wavelengths of 530 $540 \mathrm{~nm}$ and emission wavelengths of 585-595 $\mathrm{nm}$. The assay was performed following the instructions provided by the manufacturer (\#700240; Cayman Chemical Company). Each sample was duplicated to create average fluorescence values.

Analysis of neuronal morphology. The morphologies of entire neurons were indicated by the expression of pEGFP-N1. Dissociated neurons grown at low density were used to determine morphological characteristics. Neurons treated with inhibitors were randomly chosen, and neurons transfected with DNA were selected by green fluorescent protein (GFP) expression. The neurons were photographed at $20 \times$ magnification using an Olympus fluorescent microscope. All processes and their branches were traced, and their numbers were counted using DP2-BSW microscope digital camera software (Olympus). The neurites that expressed Ankyrin $\mathrm{G}$ in the initial segment were taken to be the axons. To analyze dendritic branching, all nonaxonal protrusions longer than $10 \mu \mathrm{m}$ originating from the cell soma were defined as primary dendrites. All protrusions originating from the primary dendrites were defined as secondary dendrites. All terminal branches of dendrites with lengths $>10 \mu \mathrm{m}$ were counted as dendritic tips (Jaworski et al., 2005). For Sholl analysis, concentric circles with $15 \mu \mathrm{m}$ differences in diameter were drawn around the cell body, and the number of dendrites crossing each circle was manually counted (Sholl, 1953; Jaworski et al., 2005).

Statistical analysis. All data are represented as the mean \pm the SEM. Comparisons between two groups were made using $t$ tests. Comparisons among three or more groups were made using one-way ANOVA analyses followed by Newman-Keuls tests. Data marked with asterisks are significantly different from the control as follows: ${ }^{\star \star \star} p<$ $0.001,{ }^{* *} p<0.01$, and ${ }^{\star} p<0.05$. 


\section{Results}

The expression and activity of PLD1 during the maturation of cultured hippocampal neurons

Primary culture of hippocampal neurons has long been a model system for studying the molecular mechanisms of neuronal development (Craig and Banker, 1994). After initially forming a lamellipodium (stage 1), neurons extend several short neurites that appear identical to one another (stage 2). About $2 \mathrm{~d}$ after plating, one of these minor neurites grows rapidly and becomes the axon (stage 3) (Dotti et al., 1988). Three or four days later, the remaining short neurites become mature dendrites (stage 4) and subsequently display dendritic spines (stage 5). To investigate the roles ofPLD1 in dendritic formation, we first examined the expression and activity of PLD1 during the maturation of cultured hippocampal neurons. The protein levels of PLD1 increased from DIV 1 to DIV 3, gradually decreased from DIV 3 to DIV7, and thereafter remained stable between DIV 7 and DIV 11 (Fig. $1 A, B$ ). In agreement with the protein levels, PLD activity increased from DIV 1 to DIV 3, subsequently decreased from DIV 3 to DIV 9, and finally remained stable between DIV 9 and DIV 11 (Fig. 1C). The protein level of PLD1 positively correlated with its activity (Fig. $1 D)$. As shown in Figure $1 E$, both the number of primary and secondary dendrites and the number of dendritic tips increased from DIV 3 to DIV 11. Intriguingly, PLD1 protein levels and PLD activity were negatively correlated with the number of dendrites and dendritic tips, which suggests that PLD1 might be involved in the maturation of dendrites as a negative regulator (Fig. $1 \mathrm{~F}-H$ ).

\section{PLD1 negatively regulates dendritic} branching

We cotransfected DIV 3 hippocampal neurons with GFP and WT-PLD1 or DN-PLD1 to increase the protein level or inhibit the activity of PLD1, respectively. To distinguish from endogenous PLD1, an HA tag was introduced into the $\mathrm{N}$ terminal of PLD1; this produced minimal interference with the normal function of PLD1 (Du et al., 2003). The coexpression of GFP and transfected PLD1 was confirmed by the immunostaining of HA in GFP-positive neurons (data not shown). To differentiate the primary dendrites and axon, we stained the neurons with antiAnkyrin G, as Ankyrin G is specifically expressed in the initial segment of the axon (Srinivasan et al., 1988; Zhou et al., 1998). Only Ankyrin G-negative neurites were selected for further analysis of dendritic morphogenesis (data not shown). The neurons were fixed $3 \mathrm{~d}$ after transfection for morphological assay. We found that WT-PLD1 decreased, whereas DN-PLD1 increased, the number of primary and secondary dendrites compared with
Vector

V14-RhoA
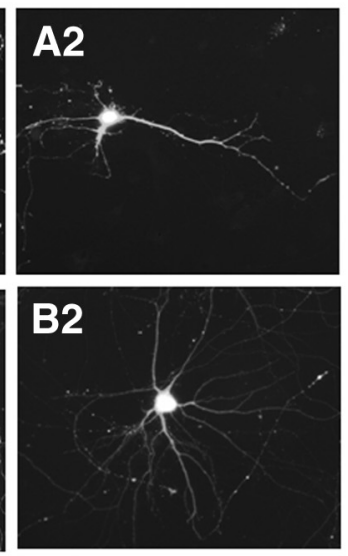

C2

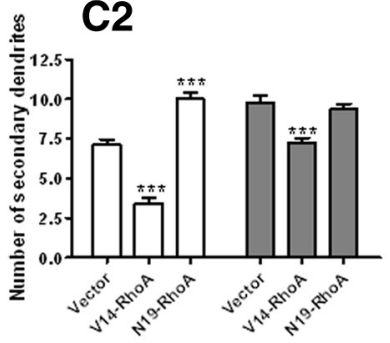

C3
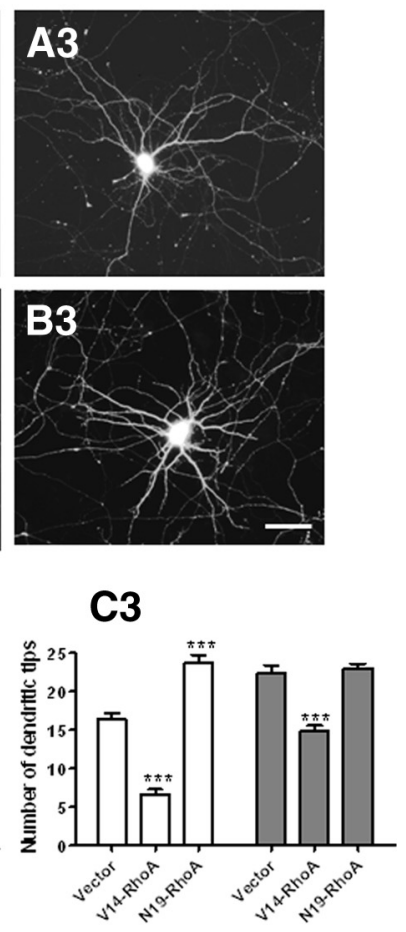

Figure 4. Knockdown of PLD1 partially rescued the reduction of dendritic branching caused by overexpression of V-14 RhoA . (C) , secondary dendrites (C2), dendritic tips (C), and Sholl analysis (CS) in $\boldsymbol{A}$ and $\boldsymbol{B}$. Control siRNA groups. $n=$ blank vector, $n=52$ neurons for V14-RhoA, $n=49$ neurons for N19-RhoA, ${ }^{* *} p<0.01,{ }^{* * *} p<0.001$, compared with blank vector, one-way ANOVA followed by Newman-Keuls multiple-comparison test. C4, Percent reductions in dendritic branching induced by V14-RhoA in the presence of Control siRNA or PLD1 siRNA. ${ }^{* *} p<0.001$, compared with Control siRNA, $t$ test.

the control HA vector (Fig. $2 A, B 1, B 2$ ). Because the dendritic tips were at the terminal branches and reflected the complexity of dendrites, we next analyzed whether the number of dendritic tips was altered by the overexpression of WT-PLD1 and DN-PLD1. Consistent with the results from primary and secondary dendritic branching, the number of dendritic tips was decreased in neurons overexpressing WT-PLD1, whereas it was increased when the activity of PLD1 was inhibited by overexpression of DN-PLD1 (Fig. 2A,B3). Similar results were obtained when we overexpressed WT-PLD1 and DN-PLD1 in DIV 6 neurons (Fig. 2C,D1D3). Finally, the effects of WT-PLD1 and DN-PLD1 on dendritic branching were confirmed by Sholl analysis (Fig. 2,B4,D4), which is the standard assay of the dendritic complexity (Sholl, 1953; Jaworski et al., 2005).

To further study the role of endogenous PLD1 in dendritic branching of hippocampal neurons, a strategy of knockdown by 
RNA interference was adopted. The efficiency of PLD1 siRNA was confirmed by the Western blot results from neuroblastoma N2a cells that were cotransfected with HA-WT-PLD1 and PLD1 siRNA (Fig. 3A2,A3). To test the efficiency of PLD1 RNA interference in neurons, we made a lentiviral PLD1 shRNA with the same target sequence as PLD1 siRNA. The PLD1 shRNA caused an $80 \%$ reduction in the expression of PLD1 in hippocampal neurons (Fig. 3A4,A5). We cotransfected GFP and Control siRNA or PLD siRNA in hippocampal neurons for $3 \mathrm{~d}$ before the analysis of dendritic branching. We found that PLD1 siRNA significantly increased dendritic branching in comparison with Control siRNA (Fig. 3B1,B2,C1-C4).

To exclude the off-target effects of PLD1 siRNA, rescue experiments were performed. An HA-PLD1 that is resistant to siRNA (hereafter referred to as RES-PLD1) was generated by replacing the nucleotides in the codon without altering the identity of the amino acids (Fig. 3A1). Western blot results showed that the PLD1 siRNA did not knock down the expression of RES-PLD1 (Fig. 3A2,A3); this result enabled us to use RES-PLD1 to rescue the dendritic phenotypes caused by PLD1 siRNA. As shown in Figure $3 B 3$ and $3 C 1-C 4$, the increase in dendritic branching due to knockdown of PLD1 was corrected by RES-PLD1, confirming the specificity of the PLD1 siRNA. Together with the results from the DN-PLD1 (Fig. 2), these data indicate that PLD1 acts as a negative regulator of dendritic branching, which is consistent with the reduction of PLD1 expression and activity during the maturation of dendrites (Fig. 1).

\section{PLD1 acts as downstream target of RhoA to suppress dendritic branching}

RhoA, one of the small Rho GTPases, has been implicated in the inhibition of dendritic growth and branching (Threadgill et al., 1997; Lee et al., 2000; Li et al., 2000; Nakayama et al., 2000; Chen and Firestein, 2007). Recent studies have suggested that RhoA directly interacts with and activates PLD1 both in vitro and in vivo (Hammond et al., 1997; Bae et al., 1998; Yamazaki et al., 1999; Du et al., 2000; Komati et al., 2005; Yoon et al., 2005; Gayral et al., 2006). In this study, we showed that PLD1 has the same effects as RhoA in reducing the number of dendritic branches. Together, these observations raise the possibility that PLD1 might be the downstream target of RhoA in the regulation of dendritic branching. In the following experiments, we tested this hypothesis in cultured hippocampal neurons.

Consistent with previous reports (Threadgill et al., 1997; Luo, 2000; Nakayama et al., 2000; Chen and Firestein, 2007), we found that overexpression of active RhoA (V14-RhoA) decreased dendritic branching, while N19-RhoA increased it (Fig. 4A,C1-C3, left three blank columns). However, there were no additive effects between N19-RhoA and PLD1 siRNA in promoting dendritic branching (Fig. 4A1,A3,B1,B3,C1-C3), suggesting that RhoA and PLD1 may share the same signaling pathway. Intriguingly, the inhibition of dendritic branching by V14-RhoA was partially rescued by knockdown of PLD1 (Fig. 4A1,A2,B1,B2,C1-C3). The percentage of reduction in dendritic branching by V14-RhoA was significantly decreased when PLD1 was knocked down (Fig. 4C4). As shown by the Sholl analysis, V14-RhoA had fewer effects in reducing dendritic complexity after knockdown of PLD1 (Fig. 4C5). These results indicate that PLD1 may act as the downstream target of RhoA in the regulation of dendritic branching, which is supported by the observations that RhoA interacts with PLD1 (Fig. 5) and activates PLD1 both in vitro and in vivo (Hammond et al., 1997; Bae et al., 1998; Yamazaki et al., 1999; Du et al., 2000; Komati et al., 2005; Yoon et al., 2005; Gayral et al., 2006).
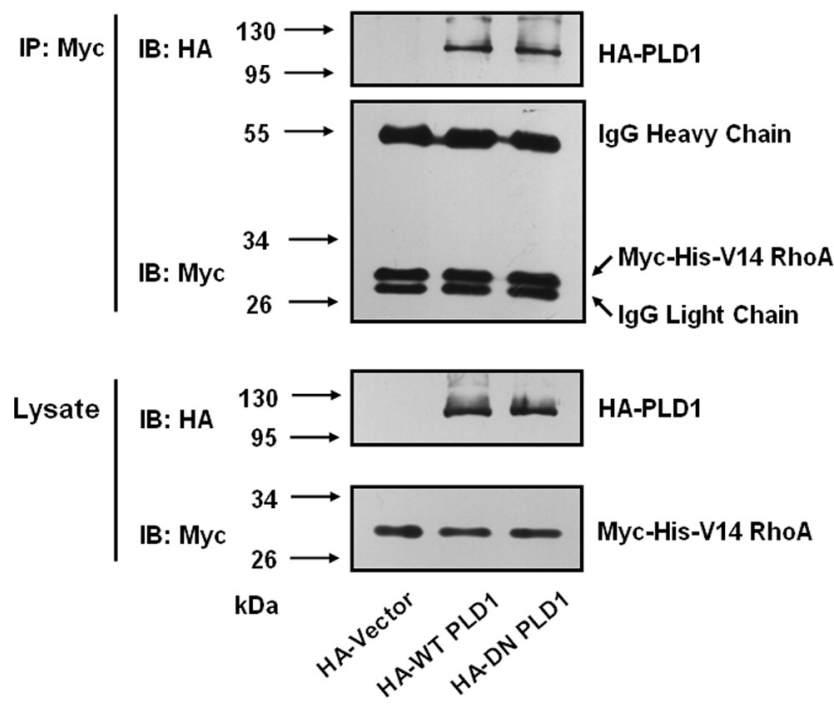

Figure 5. Coimmunoprecipitation (IP) of HA-WT-PLD1, HA-DN-PLD1, and Myc-His-V14RhoA in N2a cells.

\section{PLD1 reduces dendritic branching through PA}

The enzymatic action of mammalian PLD1 produces PA and choline. Because free choline is not thought to fulfill any intracellular signaling role (Pelech and Vance, 1984), most of the biological function of PLD1 is thought to be mediated by PA, which is a bioactive lipid (Frohman et al., 1999; Jenkins and Frohman, 2005; Cockcroft, 2009). Next, we tested whether the effects of PLD1 on dendritic branching depend on PA. To this end, we overexpressed PLD1 in hippocampal neurons with the application of $0.5 \%$ 1-butanol in the culture medium. We found that 1-butanol can block the production of PA catalyzed by PLD (Fig. 6 C6) (Chen et al., 1997; Siddhanta et al., 2000). Interestingly, the neurons treated with 1-butanol had more dendritic branching than the neurons treated with 2-butanol (the inactive analog of 1-butanol) (Fig. 6A1,B1,C1-C3, vector columns), which suggests a role of endogenous PA and PLD activity in the regulation of dendritic branching. Moreover, 1-butanol rescued the reduction of dendritic branching caused by overexpression of WT-PLD1 (Fig. 6A1,A2,B1,B2,C1-C3). The suppression of dendritic branching and complexity by overexpression of WT-PLD1 were significantly restored in 1-butanol-treated neurons compared with control neurons (Fig. 6C4,C5). These results indicate that PLD1 inhibits dendritic branching through PA.

As mentioned above, PLD1 acts as one of the downstream targets of RhoA in reducing dendritic branching. If PLD1 inhibits dendritic branching through PA, we speculated that PA should also act as the downstream target of RhoA in the regulation of dendritic branching. To test this hypothesis further, we transfected hippocampal neurons with active RhoA (V14-RhoA) in the presence of 1-butanol or its inactive analog, 2-butonal. We found that the inhibition of dendritic branching and complexity by V14-RhoA was partially restored by 1-butanol in comparison with 2-butonal (Fig. 7). These results suggested that PA is also involved in the effects of RhoA on dendritic branching. Together, these data support the working model that RhoA, PLD1, and PA may constitute one signaling pathway in the regulation of dendritic branching.

\section{Discussion}

In this study, we have demonstrated that PLD1 and its enzymatic product PA act downstream of RhoA in suppressing dendritic 
growth and branching. Several lines of evidence support our hypothesis. First, RhoA can interact with PLD1 when they are coexpressed in N2a cells, which is consistent with previous studies (Hammond et al., 1997; Bae et al., 1998; Yamazaki et al., 1999, Du et al., 2000; Komati et al., 2005; Yoon et al., 2005; Gayral et al., 2006). Second, the reduction of dendritic branching caused by active RhoA can be partially rescued by PLD1 siRNA. Third, 1-butonal, which blocks the production of PA by PLD (Chen et al., 1997; Siddhanta et al., 2000), reduced the efficacy with which PLD1 and RhoA suppressed dendritic branching. Most of the known effectors of RhoA in dendritic morphogenesis belong to protein kinases such as Rho kinase and LIM kinase 1 (Maekawa et al., 1999; Ohashi et al., 2000; Lou et al., 2001; Lin et al., 2003; Montanez et al., 2009; Fonseca et al., 2010). In this study, we identified a lipid messenger, PA, as a novel downstream target of RhoA in the regulation of dendritic branching, which will expand our understanding of how RhoA signaling regulates dendritic morphogenesis.

We could not exclude the possibility that PLD1 regulates dendritic branching through the interaction with signaling proteins other than PA. However, most of PLD1 function identified so far depends on PA or the metabolites of PA (Cai et al., 2006; Gayral et al., 2006; Zeniou-Meyer et al., 2007; Hashimoto et al., 2008; Disse et al., 2009; Bach et al., 2010; Elvers et al., 2010), because PA is the only bioactive lipid among the enzymatic products of PLD1. Here we showed that PA was one of the critical molecules that execute the effects of PLD1 on dendritic branching. Exactly how PA is involved in dendritic branching is not clear. Several signaling pathways could mediate the effects of PA on dendritic branching. PA can be metabolized to other lipids with potent bioactivity. For instance, PA can be converted to diacylglycerol and lysophosphatidic acid (LPA). LPA has been shown to induce the retraction of neurites (Tigyi and Miledi, 1992; Jalink et al., 1993, 1994). PA can recruit some signaling molecules, such as ADP-ribosylation factor 6 (Manifava et al., 2001), which has been demonstrated to reduce dendritic branching (Hernández-Deviez et al., 2002; Sakagami et al., 2004). PA also activates certain protein kinases, such as phosphatidylinositol 4-phosphate 5-kinase (PIP5K) through direct interaction (Moritz et al., 1992; Jenkins et al., 1994). Overexpression of PIP5K was sufficient to induce neurite retraction (Halstead et al., 2010), which is similar with the dendritic phenotypes caused by overexpression of PLD1. Moreover, the activity of PIP5K is essential for neurite retraction in response to LPA (van Horck et al., 2002; Yamazaki et al., 2002), one metabolite of PA. In hippocampal neurons, the axon branching was inhibited by overexpression of PIP5K (Hernández-Deviez et al., 2004). Future
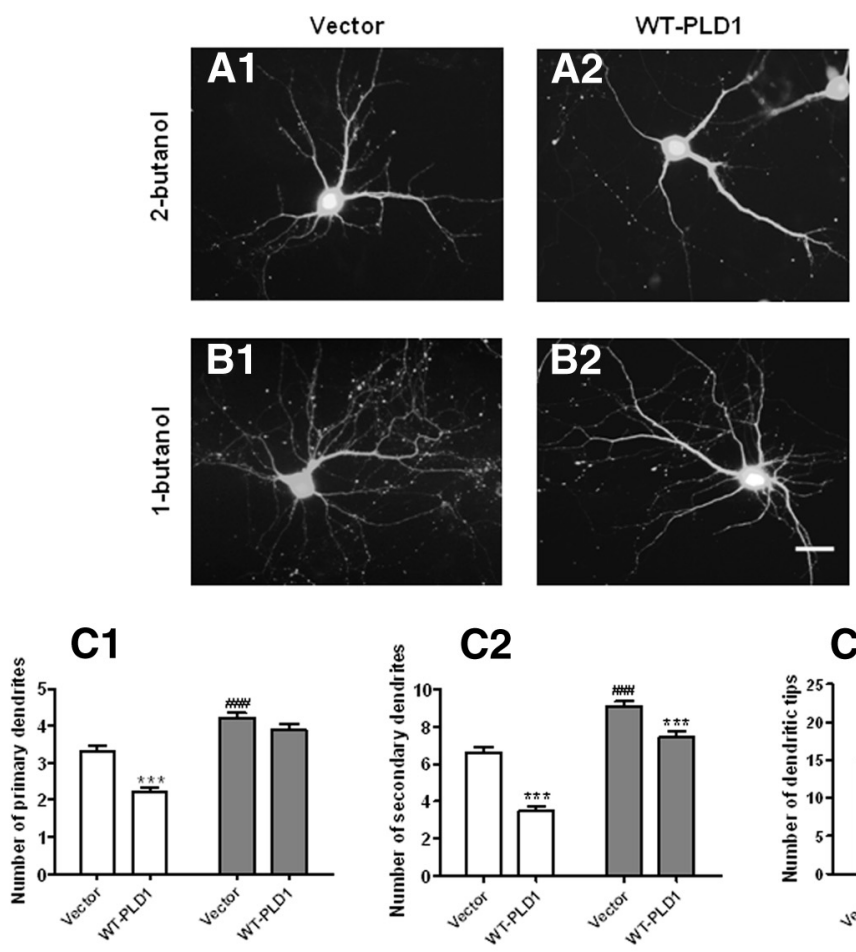

C3

. Use of 1-butanol to ameliorate the dendritic phenotypes caused by overexpression of WT-PLD1. A1, A2, Represen$n=41$ for blank vector, $n=49$ for WT-PLD1; 1-butanol-treated neurons: $n=48$ for blank vector, $n=49$ for WT-PLD1, ${ }^{*} p<$ resence of 2-butonal or 1-butonal. ${ }^{* * *} p<0.001$, compared with 2-butonal-treated neurons, $t$ test. C6, Quantification of PA concentration in the presence of 1-butanol or 2-butanol. ${ }^{* *} p<0.01$, compared with 2-butonal-treated neurons, $t$ test.

studies will address the role of PIP5K signaling in dendritic branching and whether PIP5K is involved in the RhoA-PLD1-PA pathway.

In agreement with the role of PLD1 as a downstream target of RhoA, we found that PLD1 itself is an intrinsic suppressor of dendritic growth and branching. Knockdown of PLD1 or inhibition of its activity increases dendritic branching, whereas overexpression of PLD1 decreases the complexity of dendrites. PLD1 acts as a negative regulator of dendritic arborization. This finding is also supported by the reduction of the expression and activity of PLD1 during dendritic maturation. PLD1 siRNA could not fully rescue the effects of RhoA on dendritic branching, which suggested that RhoA has other downstream signaling pathways in addition to PLD1 and PA. Several protein kinases, such as Rho kinase and LIM kinase 1, have been implicated in mediating the biological functions of RhoA (Matsui et al., 1996; Maekawa et al., 1999; Ohashi et al., 2000). Some of these kinases might cross talk with PLD1, as it has been shown that PLD1 could be activated by Rho kinase (Schmidt et al., 1999). Interestingly, Rho kinase can also inhibit dendritic branching in hippocampal 

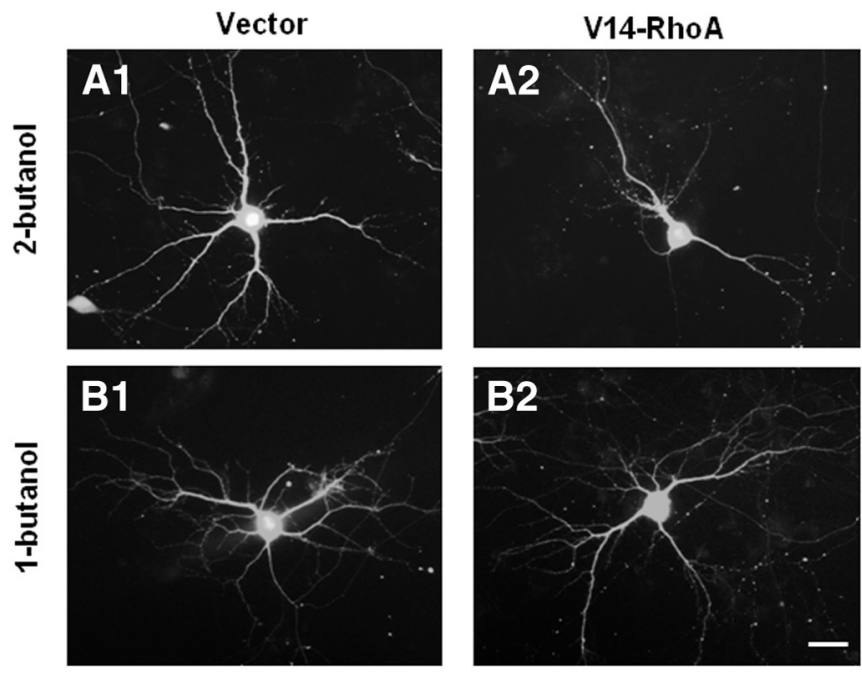
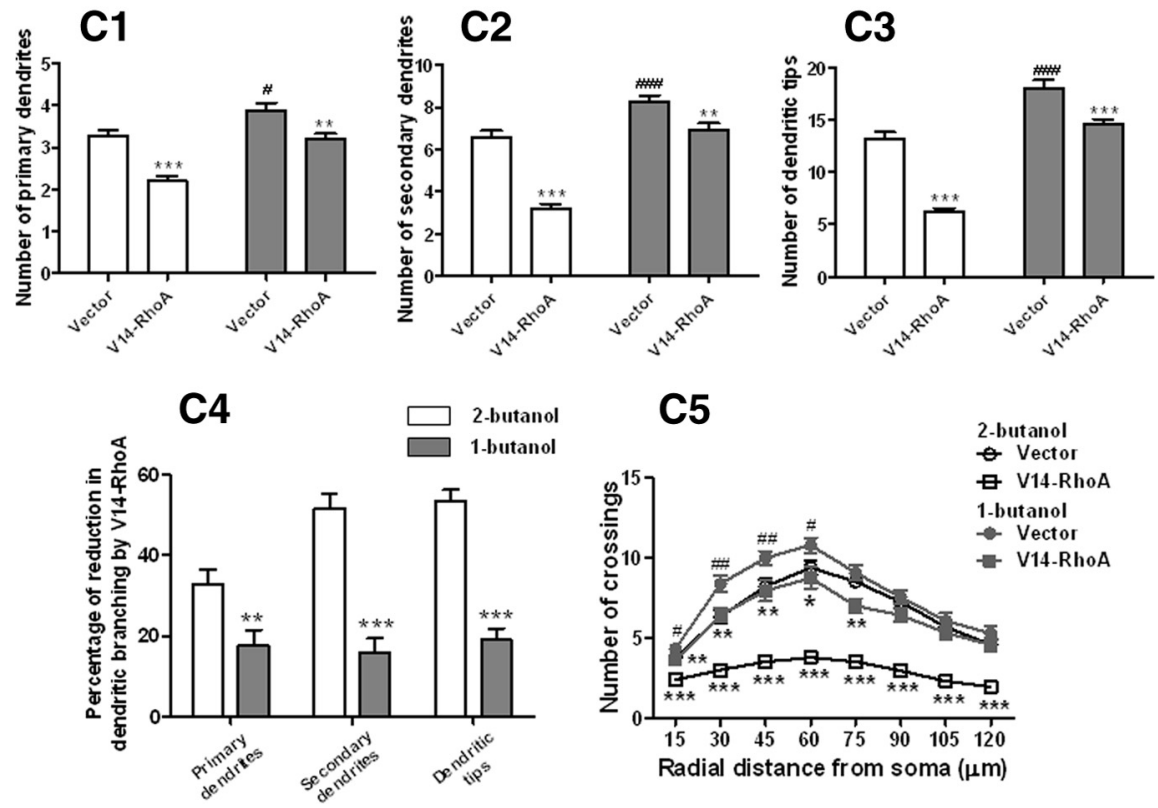

Figure 7. Use of 1-butanol to partially restore the decreased dendritic branching caused by overexpression of V14-RhoA. $\boldsymbol{A}$ 1, $A 2$, Representative images of 2-butanol-treated neurons transfected with control vector (A1) or V14-RhoA (A2). B1, B2, Representative images of 1-butanol-treated neurons transfected with control vector (B1) or V14-RhoA (B2). Scale bar, $50 \mu \mathrm{m}$. C1-C3, C5, Quantification of primary dendrites (C1), secondary dendrites (C2), dendritic tips (C3), and Sholl analysis (C5) in $\boldsymbol{A}$ and $\boldsymbol{B}$. 2-butanol-treated neurons: $n=44$ for control vector; $n=50$ for V14-RhoA; 1 -butanol-treated neurons: $n=41$ for control vector, $n=49$ forV14-RhoA, ${ }^{*} p<0.05,{ }^{* *} p<0.01,{ }^{* * *} p<0.001$, compared with control vector, $t$ test, ${ }^{\#} p<0.05,{ }^{\# \#} p<0.01,{ }^{\# \# \# p<}$ 0.001 , compared with blank vector in 2-butanol group, $t$ test. $(4$, Percent reductions in dendritic branching caused by V14-RhoA in the presence of 2-butonal or 1-butonal. ${ }^{* *} p<0.01,{ }^{* * *} p<0.001$, compared with 2-butonal-treated neurons, $t$ test. identity of the neurites (i.e., axons or dendrites). Intriguingly, PLD1 has also been implicated in calcium-dependent exocytosis (Jones et al., 1999; Bader and Vitale, 2009) and neurotransmitter release (Humeau et al., 2001). Together, these observations demonstrated the potentially important roles of PLD1 in both neural development and neurotransmission.

\section{References}

Bach AS, Enjalbert S, Comunale F, Bodin S, Vitale N, Charrasse S, Gauthier-Rouvière C (2010) ADP-ribosylation factor 6 regulates mammalian myoblast fusion through phospholipase D1 and phosphatidylinositol 4,5-bisphosphate signaling pathways. Mol Biol Cell 21:2412-2424.

Bader MF, Vitale N (2009) Phospholipase D in calcium-regulated exocytosis: lessons from chromaffin cells. Biochim Biophys Acta 1791: 936-941.

Bae CD, Min DS, Fleming IN, Exton JH (1998) Determination of interaction sites on the small $G$ protein RhoA for phospholipase D. J Biol Chem 273:11596-11604.

Cai D, Zhong M, Wang R, Netzer WJ, Shields D, Zheng H, Sisodia SS, Foster DA, Gorelick FS, Xu H, Greengard P (2006) Phospholipase D1 corrects impaired betaAPP trafficking and neurite outgrowth in familial Alzheimer's disease-linked presenilin-1 mutant neurons. Proc Natl Acad Sci U S A 103:1936-1940.

Chen H, Firestein BL (2007) RhoA regulates dendrite branching in hippocampal neurons by decreasing cypin protein levels. J Neurosci 27:8378-8386.

Chen YG, Siddhanta A, Austin CD, Hammond SM, Sung TC, Frohman MA, Morris AJ, Shields D (1997) Phospholipase D stimulates release of nascent secretory vesicles from the trans-Golgi network. J Cell Biol 138:495-504.

Cockcroft S (1996) Phospholipase D: regulation by GTPases and protein kinase $\mathrm{C}$ and physiological relevance. Prog Lipid Res 35:345-370.

Cockcroft S (2009) Phosphatidic acid regulation of phosphatidylinositol 4-phosphate 5-kinases. Biochim Biophys Acta 1791: 905-912.

Craig AM, Banker G (1994) Neuronal polarity. Annu Rev Neurosci 17:267-310.

Disse J, Vitale N, Bader MF, Gerke V (2009) Phospholipase D1 is specifically required for regulated secretion of von Willebrand factor from endothelial cells. Blood 113:973-980.

neurons (Nakayama et al., 2000), which raises the possibility that PLD1 may also act downstream of Rho kinase in the regulation of dendritic branching.

Our work corroborates recent findings that PLD1 regulates neurite growth or initiation. PLD1 was involved in basic fibroblast growth factor-induced neurite outgrowth in H19-7 cells (Oh et al., 2007). PLD1 was also important in neurite initiation in neural stem cells (Sung et al., 2001; Yoon et al., 2005). In this study, we found that PLD1 specifically restricted dendritic branching when the expression or activity of PLD1 was manipulated during the maturation of dendrites, i.e., from DIV 3 to DIV 9 in cultured hippocampal neurons. The differences between the previous studies and our results may be due to the type of cells used and/or the different developmental stages or the specific
Dotti CG, Sullivan CA, Banker GA (1988) The establishment of polarity by hippocampal neurons in culture. J Neurosci 8:1454-1468.

Du G, Altshuller YM, Kim Y, Han JM, Ryu SH, Morris AJ, Frohman MA (2000) Dual requirement for rho and protein kinase $C$ in direct activation of phospholipase D1 through $\mathrm{G}$ protein-coupled receptor signaling. Mol Biol Cell 11:4359-4368.

Du G, Altshuller YM, Vitale N, Huang P, Chasserot-Golza S, Morris AJ, Bader MF, Frohman MA (2003) Regulation of phospholipase D1 subcellular cycling through coordination of multiple membrane association motifs. J Cell Biol 162:305-315.

Elvers M, Stegner D, Hagedorn I, Kleinschnitz C, Braun A, Kuijpers ME, Boes M, Chen Q, Heemskerk JW, Stoll G, Frohman MA, Nieswandt B (2010) Impaired alpha(IIb)beta(3) integrin activation and shear-dependent thrombus formation in mice lacking phospholipase D1. Sci Signal 3: ra1.

Exton JH (1999) Regulation of phospholipase D. Biochim Biophys Acta 1439:121-133. 
Fonseca AV, Freund D, Bornhäuser M, Corbeil D (2010) Polarization and migration of hematopoietic stem and progenitor cells rely on the RhoA/ ROCK I pathway and an active reorganization of the microtubule network. J Biol Chem 285:31661-31671.

Frohman MA, Sung TC, Morris AJ (1999) Mammalian phospholipase D structure and regulation. Biochim Biophys Acta 1439:175-186.

Gayral S, Déléris P, Laulagnier K, Laffargue M, Salles JP, Perret B, Record M, Breton-Douillon M (2006) Selective activation of nuclear phospholipase D-1 by g protein-coupled receptor agonists in vascular smooth muscle cells. Circ Res 99:132-139.

Gibbs TC, Meier KE (2000) Expression and regulation of phospholipase D isoforms in mammalian cell lines. J Cell Physiol 182:77-87.

Halstead JR, Savaskan NE, van den Bout I, Van Horck F, HajdoMilasinovic A, Snell M, Keune WJ, Ten Klooster JP, Hordijk PL, Divecha N (2010) Rac controls PIP5K localisation and PtdIns(4,5)P synthesis, which modulates vinculin localisation and neurite dynamics. J Cell Sci 123:3535-3546.

Hammond SM, Jenco JM, Nakashima S, Cadwallader K, Gu Q, Cook S, Nozawa Y, Prestwich GD, Frohman MA, Morris AJ (1997) Characterization of two alternately spliced forms of phospholipase D1. Activation of the purified enzymes by phosphatidylinositol 4,5-bisphosphate, ADPribosylation factor, and Rho family monomeric GTP-binding proteins and protein kinase C-alpha. J Biol Chem 272:3860-3868.

Hashimoto Y, Okiyoneda T, Harada K, Ueno K, Sugahara T, Yamashita A, Shuto T, Suico MA, Kai H (2008) Phosphatidic acid metabolism regulates the intracellular trafficking and retrotranslocation of CFTR. Biochim Biophys Acta 1783:153-162.

Hayakawa K, Nakashima S, Ito Y, Mizuta K, Miyata H, Nozawa Y (1999) Increased expression of phospholipase D1 mRNA during cAMP- or NGFinduced differentiation in PC12 cells. Neurosci Lett 265:127-130.

Hernández-Deviez DJ, Casanova JE, Wilson JM (2002) Regulation of dendritic development by the ARF exchange factor ARNO. Nat Neurosci 5:623-624.

Hernández-Deviez DJ, Roth MG, Casanova JE, Wilson JM (2004) ARNO and ARF6 regulate axonal elongation and branching through downstream activation of phosphatidylinositol 4-phosphate 5-kinase alpha. Mol Biol Cell 15:111-120.

Humeau Y, Vitale N, Chasserot-Golaz S, Dupont JL, Du G, Frohman MA, Bader MF, Poulain B (2001) A role for phospholipase D1 in neurotransmitter release. Proc Natl Acad Sci U S A 98:15300-15305.

Jalink K, Eichholtz T, Postma FR, van Corven EJ, Moolenaar WH (1993) Lysophosphatidic acid induces neuronal shape changes via a novel, receptor-mediated signaling pathway: similarity to thrombin action. Cell Growth Differ 4:247-255.

Jalink K, van Corven EJ, Hengeveld T, Morii N, Narumiya S, Moolenaar WH (1994) Inhibition of lysophosphatidate- and thrombin-induced neurite retraction and neuronal cell rounding by ADP ribosylation of the small GTP-binding protein Rho. J Cell Biol 126:801-810.

Jan YN, Jan LY (2010) Branching out: mechanisms of dendritic arborization. Nat Rev Neurosci 11:316-328.

Jaworski J, Spangler S, Seeburg DP, Hoogenraad CC, Sheng M (2005) Control of dendritic arborization by the phosphoinositide-3'-kinase-Aktmammalian target of rapamycin pathway. J Neurosci 25:11300-11312.

Jenkins GM, Frohman MA (2005) Phospholipase D: a lipid centric review. Cell Mol Life Sci 62:2305-2316.

Jenkins GH, Fisette PL, Anderson RA (1994) Type I phosphatidylinositol 4-phosphate 5-kinase isoforms are specifically stimulated by phosphatidic acid. J Biol Chem 269:11547-11554.

Jones D, Morgan C, Cockcroft S (1999) Phospholipase D and membrane traffic. Potential roles in regulated exocytosis, membrane delivery and vesicle budding. Biochim Biophys Acta 1439:229-244.

Komati H, Naro F, Mebarek S, De Arcangelis V, Adamo S, Lagarde M, Prigent AF, Némoz G (2005) Phospholipase D is involved in myogenic differentiation through remodeling of actin cytoskeleton. Mol Biol Cell 16:1232-1244.

Lee T, Winter C, Marticke SS, Lee A, Luo L (2000) Essential roles of Drosophila RhoA in the regulation of neuroblast proliferation and dendritic but not axonal morphogenesis. Neuron 25:307-316.

Li Z, Van Aelst L, Cline HT (2000) Rho GTPases regulate distinct aspects of dendritic arbor growth in Xenopus central neurons in vivo. Nat Neurosci 3:217-225.

Lin T, Zeng L, Liu Y, DeFea K, Schwartz MA, Chien S, Shyy JY (2003) Rho-
ROCK-LIMK-cofilin pathway regulates shear stress activation of sterol regulatory element binding proteins. Circ Res 92:1296-1304.

Lou Z, Billadeau DD, Savoy DN, Schoon RA, Leibson PJ (2001) A role for a RhoA/ROCK/LIM-kinase pathway in the regulation of cytotoxic lymphocytes. J Immunol 167:5749-5757.

Luo L (2000) Rho GTPases in neuronal morphogenesis. Nat Rev Neurosci $1: 173-180$.

Maekawa M, Ishizaki T, Boku S, Watanabe N, Fujita A, Iwamatsu A, Obinata T, Ohashi K, Mizuno K, Narumiya S (1999) Signaling from Rho to the actin cytoskeleton through protein kinases ROCK and LIM-kinase. Science 285:895-898.

Manifava M, Thuring JW, Lim ZY, Packman L, Holmes AB, Ktistakis NT (2001) Differential binding of traffic-related proteins to phosphatidic acid- or phosphatidylinositol (4,5)-bisphosphate-coupled affinity reagents. J Biol Chem 276:8987-8994.

Matsui T, Amano M, Yamamoto T, Chihara K, Nakafuku M, Ito M, Nakano T, Okawa K, Iwamatsu A, Kaibuchi K (1996) Rho-associated kinase, a novel serine/threonine kinase, as a putative target for small GTP binding protein Rho. EMBO J 15:2208-2216.

Meier KE, Gibbs TC, Knoepp SM, Ella KM (1999) Expression of phospholipase D isoforms in mammalian cells. Biochim Biophys Acta 1439:199-213.

Meng Y, Zhang Y, Tregoubov V, Janus C, Cruz L, Jackson M, Lu WY, MacDonald JF, Wang JY, Falls DL, Jia Z (2002) Abnormal spine morphology and enhanced LTP in LIMK-1 knockout mice. Neuron 35:121-133.

Montanez E, Wickström SA, Altstätter J, Chu H, Fässler R (2009) Alphaparvin controls vascular mural cell recruitment to vessel wall by regulating RhoA/ROCK signaling. EMBO J 28:3132-3144.

Morita SY, Ueda K, Kitagawa S (2009) Enzymatic measurement of phosphatidic acid in cultured cells. J Lipid Res 50:1945-1952.

Moritz A, De Graan PN, Gispen WH, Wirtz KW (1992) Phosphatidic acid is a specific activator of phosphatidylinositol-4-phosphate kinase. J Biol Chem 267:7207-7210.

Nakayama AY, Harms MB, Luo L (2000) Small GTPases Rac and Rho in the maintenance of dendritic spines and branches in hippocampal pyramidal neurons. J Neurosci 20:5329-5338.

Oh DY, Park SY, Cho JH, Lee KS, Min do S, Han JS (2007) Phospholipase D1 activation through Src and Ras is involved in basic fibroblast growth factor-induced neurite outgrowth of H19-7 cells. J Cell Biochem 101:221-234.

Ohashi K, Nagata K, Maekawa M, Ishizaki T, Narumiya S, Mizuno K (2000) Rho-associated kinase ROCK activates LIM-kinase 1 by phosphorylation at threonine 508 within the activation loop. J Biol Chem 275:3577-3582.

Pelech SL, Vance DE (1984) Regulation of phosphatidylcholine biosynthesis. Biochim Biophys Acta 779:217-251.

Rudge SA, Wakelam MJ (2009) Inter-regulatory dynamics of phospholipase D and the actin cytoskeleton. Biochim Biophys Acta 1791:856-861.

Sakagami H, Matsuya S, Nishimura H, Suzuki R, Kondo H (2004) Somatodendritic localization of the mRNA for EFA6A, a guanine nucleotide exchange protein for ARF6, in rat hippocampus and its involvement in dendritic formation. Eur J Neurosci 19:863-870.

Schmidt M, Voss M, Weernink PA, Wetzel J, Amano M, Kaibuchi K, Jakobs KH (1999) A role for Rho-kinase in Rho-controlled phospholipase D stimulation by the $\mathrm{m} 3$ muscarinic acetylcholine receptor. J Biol Chem 274:14648-14654.

Sholl DA (1953) Dendritic organization in the neurons of the visual and motor cortices of the cat. J Anat 87:387-406.

Siddhanta A, Backer JM, Shields D (2000) Inhibition of phosphatidic acid synthesis alters the structure of the Golgi apparatus and inhibits secretion in endocrine cells. J Biol Chem 275:12023-12031.

Srinivasan Y, Elmer L, Davis J, Bennett V, Angelides K (1988) Ankyrin and spectrin associate with voltage-dependent sodium channels in brain. $\mathrm{Na}-$ ture 333:177-180.

Sung JY, Lee SY, Min DS, Eom TY, Ahn YS, Choi MU, Kwon YK, Chung KC (2001) Differential activation of phospholipases by mitogenic EGF and neurogenic PDGF in immortalized hippocampal stem cell lines. J Neurochem 78:1044-1053.

Threadgill R, Bobb K, Ghosh A (1997) Regulation of dendritic growth and remodeling by Rho, Rac, and cdc42. Neuron 19:625-634.

Tigyi G, Miledi R (1992) Lysophosphatidates bound to serum albumin activate membrane currents in Xenopus oocytes and neurite retraction in PCI2 pheochromocytoma cells. J Biol Chem 267:21360-21367. 
van Horck FP, Lavazais E, Eickholt BJ, Moolenaar WH, Divecha N (2002) Essential role of type I(alpha) phosphatidylinositol 4-phosphate 5-kinase in neurite remodeling. Curr Biol 12:241-245.

Yamazaki M, Miyazaki H, Watanabe H, Sasaki T, Maehama T, Frohman MA, Kanaho Y (2002) Phosphatidylinositol 4-phosphate 5-kinase is essential for ROCK-mediated neurite remodeling. J Biol Chem 277:17226-17230.

Yamazaki M, Zhang Y, Watanabe H, Yokozeki T, Ono S, Kaibuchi K, Shibata H, Mukai H, Ohno Y, Frohman MA, Kanaho Y (1999) Interaction of the small $\mathrm{G}$ protein RhoA with the C terminus of human phospholipase D1. J Biol Chem 274:6035-6038.

Yoon MS, Yon C, Park SY, Oh DY, Han AH, Kim DS, Han JS (2005) Role of phospholipase D1 in neurite outgrowth of neural stem cells. Biochem Biophys Res Commun 329:804-811.

Zeniou-Meyer M, Zabari N, Ashery U, Chasserot-Golaz S, Haeberlé AM,
Demais V, Bailly Y, Gottfried I, Nakanishi H, Neiman AM, Du G, Frohman MA, Bader MF, Vitale N (2007) Phospholipase D1 production of phosphatidic acid at the plasma membrane promotes exocytosis of large dense-core granules at a late stage. J Biol Chem 282: 21746-21757.

Zhang Y, Huang P, Du G, Kanaho Y, Frohman MA, Tsirka SE (2004) Increased expression of two phospholipase D isoforms during experimentally induced hippocampal mossy fiber outgrowth. Glia 46:74-83.

Zhang Y, Kanaho Y, Frohman MA, Tsirka SE (2005) Phospholipase D1promoted release of tissue plasminogen activator facilitates neurite outgrowth. J Neurosci 25:1797-1805.

Zhou D, Lambert S, Malen PL, Carpenter S, Boland LM, Bennett V (1998) AnkyrinG is required for clustering of voltage-gated $\mathrm{Na}$ channels at axon initial segments and for normal action potential firing. J Cell Biol 143: 1295-1304. 